
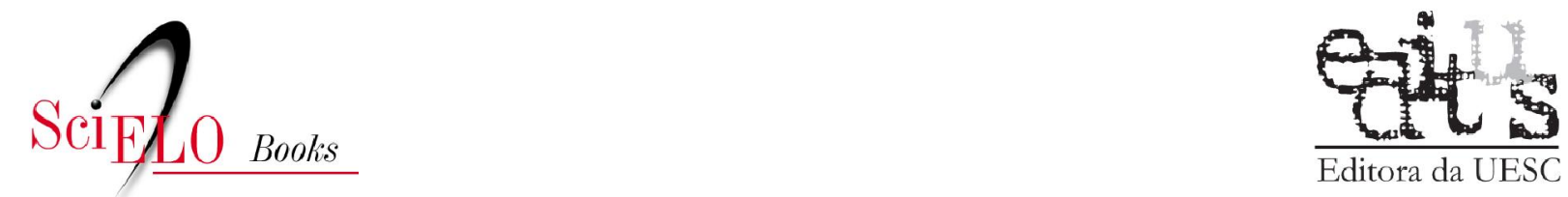

Editora da UESC

\title{
11 Manutenção de projetos de recuperação ambiental
}

\author{
Danilo Sette de Almeida
}

SciELO Books / SciELO Livros / SciELO Libros

ALMEIDA, DS. Manutenção de projetos de recuperação ambiental. In: Recuperação ambiental da Mata Atlântica [online].3rd ed. rev. and enl. Ilhéus, BA: Editus, 2016, pp. 160-168. ISBN 978-85-

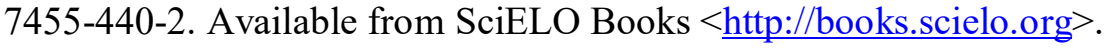

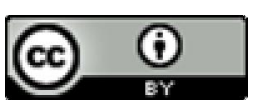

All the contents of this work, except where otherwise noted, is licensed under a Creative Commons Attribution 4.0 International license.

Todo o conteúdo deste trabalho, exceto quando houver ressalva, é publicado sob a licença Creative Commons Atribição 4.0.

Todo el contenido de esta obra, excepto donde se indique lo contrario, está bajo licencia de la licencia $\underline{\text { Creative }}$ Commons Reconocimento 4.0. 


$$
11
$$

\section{MANUTENÇÃO DE PROJETOS DE RECUPERAÇÃO AMBIENTAL}




\subsection{Manutenção dos plantios}

$\mathrm{U}$

ma das etapas mais importantes em todo processo de recuperação de uma área degradada é a manutenção do plantio. Em função, principalmente da presença de plantas invasoras na área (que vão competir ou até mesmo matar as mudas das espécies introduzidas), deve ser planejada a frequência das manutenções, envolvendo as operações de replantio de mudas mortas, coroamento (limpeza ao redor das mudas), adubação de cobertura, combate a formigas cortadeiras, reparos de cercas etc. Em áreas antes ocupadas por determinados tipos de gramíneas, como braquiárias ou colonião, por exemplo, faz-se necessário manter a área ao redor das mudas sem vegetação competidora. Esta limpeza ao redor das mudas pode ser realizada com aplicação de herbicidas ou capina manual (coroamento) até o estabelecimento do componente arbóreo e sombreamento, quando estas gramíneas serão naturalmente eliminadas do sistema florestal. Os problemas comumente encontrados em áreas recuperadas, gerando a necessidade de manutenção, são mostrados no QUADRO 1, abaixo:

QUADRO 1 - Problemas comuns que geram necessidade de manutenção de áreas

\begin{tabular}{|l|l|}
\hline \multicolumn{1}{|c|}{ PROBLEMA APRESENTADO } & \multicolumn{1}{c|}{ SOLUÇÕES VIÁVEIS } \\
\hline Mortalidade de mudas plantadas. & Replantio de mudas. \\
\hline Presença de vegetação competidora. & Capina mecânica ou química, roçada da área. \\
\hline Seca pronunciada. & Irrigação das mudas (manhã e final da tarde). \\
\hline $\begin{array}{l}\text { Presença de plantas competidoras } \\
\text { nas covas. }\end{array}$ & Coroamento ao redor das mudas. \\
\hline $\begin{array}{l}\text { Entrada e presença de animais } \\
\text { domésticos. }\end{array}$ & Revisão do cercamento da área. \\
\hline Risco de incêndios. & Revisar o sistema de aceiros. \\
\hline $\begin{array}{l}\text { Mudas plantadas apresentando pro- } \\
\text { blemas nutricionais. }\end{array}$ & $\begin{array}{l}\text { Aplicação de adubação de cobertura nas } \\
\text { covas das mudas plantadas. }\end{array}$ \\
\hline Ataque de formigas cortadeiras. & Combate às formigas cortadeiras. \\
\hline
\end{tabular}

Em áreas, onde a aplicação de herbicidas pode comprometer o sistema, o custo de recuperação (devido ao custo de manutenção - capinas manuais mais frequentes) é elevado, podemos utilizar algumas alternativas ao redor das mudas, visando o impedimento da formação/aparecimento da vegetação competidora. A aplicação 
de matéria orgânica (mulching) morta ao redor das mudas, papel jornal ou papelão, pode solucionar este problema, principalmente, em áreas onde não podemos fazer aplicação do herbicida. A colocação da camada orgânica (mulching), jornal ou papelão ao redor das mudas (coroa), garante a umidade do solo e evita o surgimento de plantas competidoras com as que foram implantadas. A colocação da "saia orgânica" deve ser realizada após o coroamento manual da área (limpeza com enxada ao redor das mudas). A FOTO 18 mostra área na qual foi colocado o papel de jornal ao redor das mudas, evitando a presença de vegetação gramínea competidora.

FOTO 18 - Colocação de matéria orgânica ao redor das mudas (mulch) visando inibir o aparecimento da vegetação competidora (pastagem de braquiária).

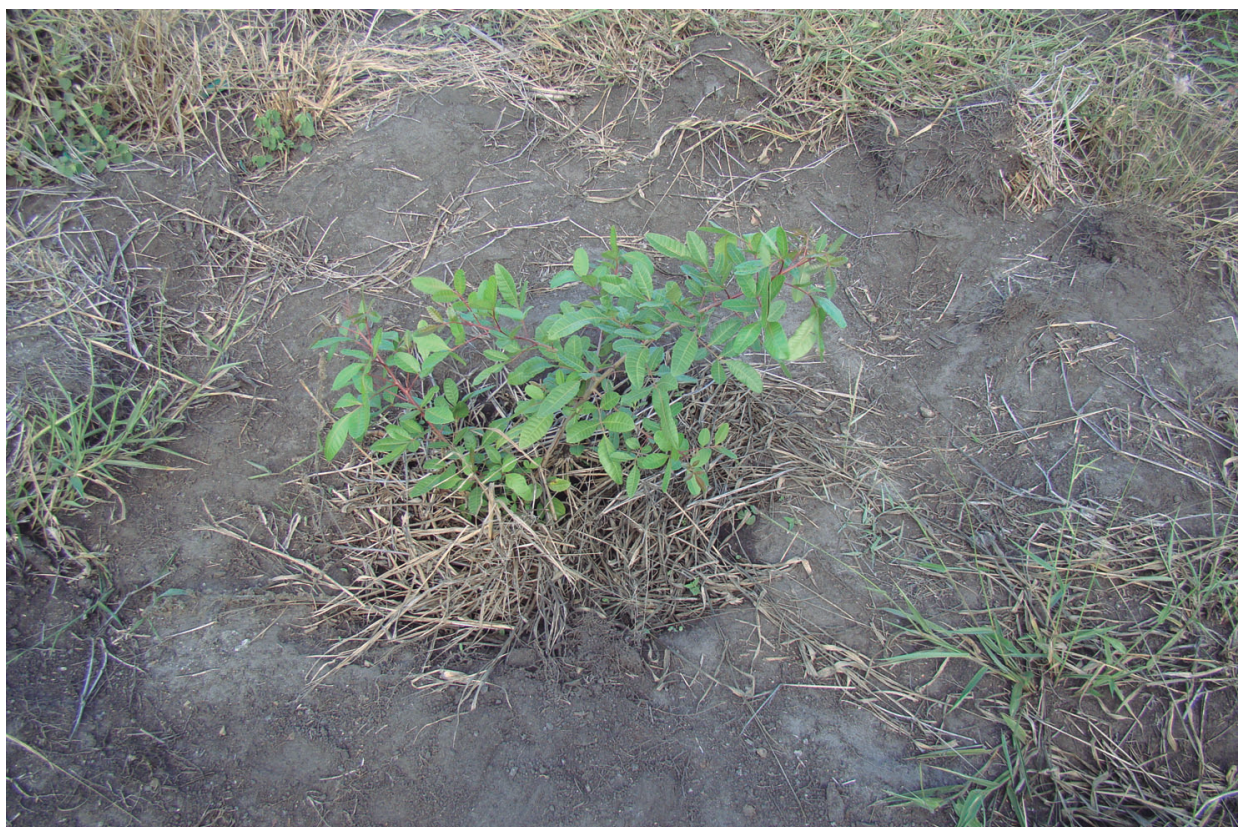

Existe uma grande deficiência na pesquisa de materiais para formação de camada orgânica morta ao redor das mudas (mulching), esta proteção tem efeitos fantásticos, eliminado custos de manutenção e garantindo o sucesso do plantio. Uma boa opção é se, na roçada e coroamento, colocarmos toda matéria orgânica oriunda destas operações, ao redor das mudas, visando manter a umidade do solo e evitar o aparecimento de plantas competidoras ao redor das plântulas introduzidas. A roçada, quando necessária, deve ser 
realizada em linhas, sempre acompanhando o sentido das curvas de nível do terreno que está sendo recuperado.

A operação de coroamento ao redor das mudas tem de ser observada e deve ser capinada, eliminando a vegetação em um raio de $60 \mathrm{~cm}$ ao redor das mudas. É importante frisar que, nesta operação, a capina e a eliminação da vegetação devem se concentrar somente ao redor das mudas, visto que, onde já existe algum tipo de cobertura, a vegetação preferencialmente não deve ser completamente eliminada, pois estas plantas exercem um papel importante na proteção e conservação dos solos. Caso esta vegetação esteja de porte mais alto, será necessária uma roçada na área de plantio, evitando a competição por luz entre a vegetação herbácea arbustiva estabelecida e as mudas plantadas.

A FOTO 19 mostra a área onde foi colocado, de forma experimental, o papelão, visando manter a umidade ao redor das mudas e reduzir o aparecimento da vegetação competidora, em especial de gramíneas.

FOTO 19 - Colocação de papelão ao redor das mudas visando inibir o aparecimento da vegetação competidora (pastagem de braquiária) e evitando o uso de herbicidas

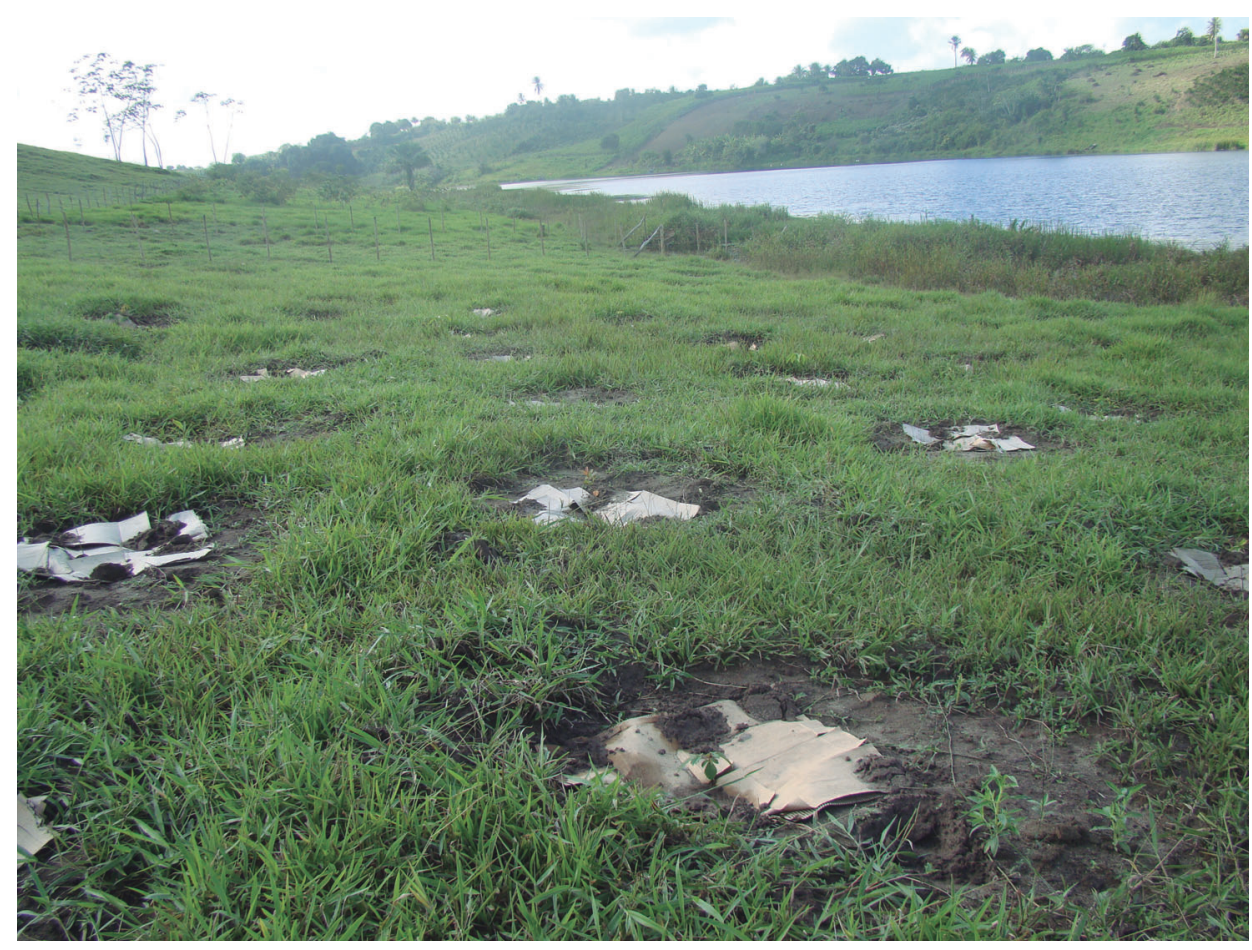


Dentre as operações realizadas na etapa de manutenção dos plantios, podemos destacar as limpezas ao redor da muda (com finalidade de eliminar plantas competidoras), esta limpeza pode ser manual com o uso de enxadas e química com aplicação de herbicidas. Destacamos também as operações de roçada, para rebaixar a vegetação vizinha das mudas plantadas, evitando competição por luz. Igualmente temos operações importantes de manutenção como o replantio, adubação de cobertura e colocação de cobertura morta. A seguir, descrevemos as operações mais comuns realizadas na fase de manutenção dos plantios de restauração ecológica.

\subsubsection{Capina manual}

Consiste na eliminação da vegetação competidora ao redor das mudas com uso de enxadas. A capina manual com enxadas pode ser realizada na área total, nas linhas de plantio, conjugadas ou não com uma roçada geral.

\subsubsection{Capina química}

Consiste na aplicação de herbicidas para eliminação da vegetação competidora presente ao redor das mudas. A capina pode ser realizada na área total (dependendo do tamanho das mudas e equipamento utilizado), nas linhas de plantio, nas entrelinhas do plantio, conjugadas ou não com uma roçada geral. Em muitos casos, a aplicação de herbicidas é proibida (como no caso de restauração de matas ciliares em reservatórios destinados a abastecimento doméstico de cidades), então é necessária a manutenção, através de capinas manuais com enxadas.

\subsubsection{Roçada}

A roçada consiste no rebaixamento da vegetação não arbórea competidora (principalmente por luz) existente na área de plantio. Esta roçada pode ser feita na área total, em linhas, de forma mecânica (através de foices), mecanizada (roçadeiras) ou química (aplicação de herbicidas). Normalmente, a vegetação existente é rebaixada para uma altura de aproximadamente 10 centímetros. 


\subsubsection{Coroamento}

É uma capina manual com retirada da vegetação competidora ao redor das mudas, normalmente, compreende uma área circular (coroa) com cerca de 50-60 cm de raio (100-120 cm de diâmetro) ao redor das mudas. Nesta área, a capina deve ser geral, eliminando toda vegetação existente. Esta operação pode ser manual (através do uso de enxadas) ou química (através da aplicação de herbicidas), sendo que a química exige que as mudas já possuam altura maior que $50 \mathrm{~cm}$, e o herbicida não atinja as folhas.

\subsubsection{Replantio}

Consiste na realização de um novo plantio das mudas (repasse) que deverá ser realizado em 30-60 dias, após o plantio inicial. O replantio deverá ser feito após avaliação do índice de mortalidade das mudas.

A experiência prática mostra que a média de mortalidade em plantios de nativas gira em torno de $5 \%$ de falhas, acima de $10 \%$ de falhas, é necessário identificar o fator gerador da mortalidade e resolver o problema (percentuais válidos para áreas de floresta ombrófila densa - Mata Atlântica).

Para o replantio, devem ser observados os mesmos parâmetros verificados para o plantio, principalmente em relação ao período chuvoso.

\subsubsection{Adubação de cobertura}

Consiste na aplicação complementar de adubo nas covas, após a operação e a adubação de plantio. Normalmente, esta adubação é feita durante as operações de manutenção (cerca de 120 dias após o plantio), quando as raízes das mudas já estão estabelecidas. Esta operação deve ser realizada após o coroamento ao redor das mudas e pode ser feita através da incorporação do adubo misturado ao solo, fazendo dois canais lado a lado da muda. Normalmente aplicamos de 150-250 gramas de adubo NPK ao redor das mudas, nesta adubação é recomendável uma adubação mais equilibrada em nutrientes ou com maior concentração de Nitrogênio e Potássio (Formulações NPK 10.0.30 ou 10.10.10, por exemplo). A adubação 
de cobertura deve também ser programada antecedendo ao período de chuvas, para melhor aproveitamento dos nutrientes do adubo pelas mudas.

\subsubsection{Colocação de cobertura morta}

Éuma operação que pode ser realizada após o plantio e revisada na manutenção. Consiste na colocação de resíduos de atividades de roçadas e coroamento ao redor das mudas, capim seco, por exemplo, nas coroas já limpas manualmente ou com herbicida.

Além de proteger a muda do aparecimento de vegetação competidora, ao redor das mudas, também mantém a umidade ao redor das mudas e reduz a necessidade de irrigação complementar e manutenção/coroamento ao redor das mudas.

\subsection{Monitoramento dos plantios}

A escolha de parâmetros, para monitoramento dos plantios de recuperação ambiental da Mata Atlântica, vai ser variável em função dos objetivos deste monitoramento. Em plantios experimentais, deve ser incorporado um maior número de variáveis para a mensuração e, em áreas de recuperação não experimentais, devem ser acompanhados os critérios ou indicadores mais simples de serem controlados periodicamente, escolhendo-se parâmetros que permitam comparar o desempenho de diferentes áreas em recuperação.

Como premissas básicas para o estabelecimento dos parâmetros de acompanhamento do desenvolvimento de plantios, temos de tomar como proposições básicas os objetivos definidos, no início dos trabalhos de plantio, isto é, a recuperação ambiental da floresta atlântica de determinada área e a recomposição da biodiversidade original, assim tomamos como base de referência o ecossistema original.

Um indicador é a medida de distância entre um objetivo ou a meta e aspectos de desempenho que devem ser avaliados, ou seja, indicadores são parâmetros que permitem avaliar atributos de um área ou processo, com objetivo de comparar tais resultados com resultados anteriores, metas ou objetivos preestabelecidos, ou ainda comparar áreas ou processos similares (FUNDAÇÃO PARA CONSERVAÇÃO E A PROTEÇÃO FLORESTAL DO ESTADO DE 
SÃO PAULO, 2004). Portanto os indicadores são parâmetros que indicam os resultados gerados pelas atividades realizadas.

Indicadores que podem ser utilizados:

- Mudas plantadas - para mudas plantadas, utilizamos critérios baseados no crescimento e desenvolvimento das plantas como: porte das mudas e plantio (altura total, altura do fuste, diâmetro do colo ou basal, DAP diâmetro a altura do peito e diâmetro da copa), riqueza do plantio (número de espécies plantadas), densidade (número de indivíduos por hectare).

- Regeneração natural (recrutamento) - número de indivíduos (não plantados) que surgem nas entrelinhas da área plantada, em recuperação. Pode ser amostrado em parcelas de área conhecida, distribuída na área, onde pode ser medida a regeneração de indivíduos novos (não plantados) que surgiram na área em recuperação.

- Diversidade da regeneração natural - diversidade de espécies da regeneração natural.

- Cobertura das copas - é medida pelo percentual de cobertura do solo pela vegetação (cobertura de copas) ou sombreamento.

- Diversidade de espécies florestais - mensurando tanto a diversidade de espécies plantadas, quanto a diversidade da regeneração natural (novos ingressos).

- Mortalidade - o índice de mortalidade, expresso em percentagem, é um bom indicador do sucesso do plantio realizado.

- Replantio - deverá ser computado e registrado o replantio realizado.

- Serrapilheira - podem ser medidos a profundidade e o peso da serrapilheira de determinada área (amostra). Também podem ser computados o peso e os nutrientes desta amostra, normalmente expressos em quilos por hectare (Kg/ha).

- Mato-competição - existência de gramíneas e de espécies invasoras.

- Ataque de pragas e doenças - presença de ataque de fungos, doenças e insetos na área recuperada. 
- Banco de sementes - indica o potencial de regeneração natural da área principalmente após distúrbio. Pode ser mensurado através de amostras coletadas em áreas conhecidas ou recolhidas no chão da floresta em recuperação.

- Chuva de sementes - compreende a queda de sementes na área em recuperação. Pode ser mensurada através da colocação de coletores dispostos na área.

- Monitoramento do componente fauna - o estudo da avifauna é hoje o parâmetro de fauna mais comumente utilizado. Em geral, fazemos o mesmo esforço de campo para comparar diferentes áreas (tempo de horas rede). Outros grupos de fauna também vêm sendo utilizados, principalmente mamíferos e formigas.

- Monitoramento do solo - esperamos que, com a implantação da vegetação, os solos também sofram mudanças com o passar do tempo. É um parâmetro interessante para monitoramento, principalmente para áreas de mineração onde, partindo de um solo geralmente exaurido, são grandes as mudanças do substrato ao longo do tempo. O solo pode ser monitorado através de sua composição química (teores de nitrogênio, fósforo, potássio etc.), de teores de matéria orgânica (um dos parâmetros que sofre maior transformação) e da composição física (densidade, porosidade e outros). Estes são bons parâmetros para monitoramento.

- Periodicidade - o monitoramento deverá ser feito periodicamente onde, em períodos regulares, são amostrados os mesmos indicadores selecionados na primeira amostragem de acompanhamento. Os parâmetros técnicos dos plantios são tomados como referência (espaçamento, diversidade de espécies utilizadas inicialmente, proporção de espécies entre os diferentes grupos ecofisiológicos). Quando da manutenção, obrigatoriamente, devem ser monitorados parâmetros como infestação de espécies invasoras, estado fitossanitário das mudas. 